\title{
Impact of Pulp on the Chemical Profile of Mango Wine
}

\author{
X. Li ${ }^{1}$, S.L. $\operatorname{Lim}^{1}$, B. Yu², P. Curran², S.-Q. Liu ${ }^{1,3 *}$
}

(1) Food Science and Technology Programme, Department of Chemistry, National University of Singapore, 3 Science Drive 3, Singapore 117543

(2) Firmenich Asia Pte Ltd, Tuas, Singapore 638377

(3) National University of Singapore (Suzhou) Research Institute, No. 377 Linquan Street, Suzhou Industrial Park, Suzhou, Jiangsu, China 215123

Submitted for publication: December 2012

Accepted for publication: March 2013

Key words: mango wine, juice, pulp, volatiles, aroma, flavour

\begin{abstract}
The aim of this study was to assess the effect of mango pulp inclusion (which mimicked the maceration step in grape wine fermentation) on the fermentation dynamics and chemical profile of mango wine, especially the volatiles. The growth of Saccharomyces cerevisiae MERIT.ferm was slower in the mango juice with pulp (uncentrifuged juice), with a corresponding slower reduction in ${ }^{\circ} \mathrm{Brix}$, relative to the juice without pulp (centrifuged juice). The utilisation of glucose, fructose and sucrose was similar in both uncentrifuged and centrifuged juices, with almost complete consumption. Citric, tartaric, malic, pyruvic and succinic acid were the major organic acids in the wines fermented from both the uncentrifuged and centrifuged juices. Citric acid decreased slightly in the macerated wine. Tartaric and malic acid decreased in both wines. Pyruvic acid increased slightly and succinic acid remained almost constant in both wines. Monoterpenes, as one of the signature aroma compounds in mango juice, decreased dramatically in both wines, but were ten times higher in the macerated wine. Terpenols were at least four times higher in the macerated wine. The macerated wine also produced higher levels of fusel alcohols and acetate esters compared to the nonmacerated wine. On the other hand, the non-macerated wine possessed a higher concentration of mediumchain fatty acids and corresponding ethyl esters. This study indicates that the inclusion of pulp in mango wine fermentation would contribute to the aroma complexity.
\end{abstract}

\section{INTRODUCTION}

Mango (Mango indica L.) is an economically important fruit in South and Southeast Asia (Tharanathan et al., 2006). However, substantial quantities of mangoes are wasted because of its short shelf life. Therefore, postharvest quality preservation via various approaches and further processing of this fruit become essential (Sivakumar et al., 2011). A possible alternative to processing and preserving mango is to ferment its juice into wine, which is helpful in keeping mango flavour characteristics for a longer period. This is possible due to the high sugar content (16 to $18 \%$ ) (with sucrose, glucose and fructose being the principal sugars) and other nutrients in fully-ripened mango fruits (Reddy \& Reddy, 2005).

The production of mango wine was first reported in the 1960s (Czyhrinciwk, 1966). In recent years, analysis of the volatile compounds of mango wine has been done on several cultivars, such as Banginapalli, Alphonso, Haden, Chok anan, Allampur baneshan, Neelam bangalora, Raspuri, R2E2 and Harum manis (Reddy \& Reddy, 2005; Reddy et al., 2010; Li et al., 2011; Pino \& Queris, 2011; Li et al., 2012). Reddy and Reddy (2005) used Saccharomyces cerevisiae together with pectinase to ferment six local varieties of Indian mango. They concluded that the ethanol level and aromatic components in mango wine were comparable to those of grape wine. Reddy et al. (2010) found isoamyl alcohol and ethyl acetate to be in amounts comparable to that of grape wine. Pino and Queris (2011) reported the main aroma-active compounds in mango wine as aldehydes, esters and alcohols by using odour activity values. They also found ethyl butanoate and decanal to be the powerful contributors to the aroma of mango wine. Li et al. (2012) differentiated the characters of mango wines fermented from three mango varieties and suggested that the Thai Nam Doc Mai mango wine was similar to white wine from grapes due to its higher production of alcohols and esters, while the Australian R2E2 wine was able to retain its original aroma due to its retention of lactones.

Wine aroma, widely considered to be a key aspect of wine quality, is the result of the interaction between fruit components and those produced during processing, fermentation and ageing. It is now well established that, apart from free aroma compounds, a significant part of several aroma compounds is accumulated in fruits as odourless non-

*Corresponding author: E-mail: chmlsq@nus.edu.sg [Tel.: +65 6516 2687; Fax: +65 67757895$]$

Aknowledgements: This work was supported, in part, by an ARF grant from the Ministry of Education of Singapore (WBS No. R-143-000-507-112) 
volatile glycosides (Adedeji et al., 1992; Drider et al., 1994). The aglycone moieties of glycosides include monoterpenes, alcohols, aldehydes, acids, esters, $\mathrm{C}_{13}$-norisoprenoids and other compounds. To date, various studies have been conducted on glycosidically-bound volatiles in different mango cultivars (Adedeji et al., 1992; Drider et al., 1994; Ollé et al., 1998; Lalel et al., 2003). Mango fruit possess glycosidases on their own and their activities are enhanced during the maturation process. The glycosidically-bound aroma compounds therefore continuously increase in the pulp as maturity progresses, but the activities of glycosidases in the fruit are greatly reduced at typical wine fermentation pH (Lalel et al., 2003). Thus, the mango pulp still contains glycosides that serve as aroma precursors and the aroma compounds can be released during fermentation, since S. cerevisiae glycosidases are able to release glycosidicallybound aroma compounds during wine fermentation (Mateo \& Stefano, 1997; Palmeri \& Spagna, 2007). However, this aspect has not been examined in mango wine fermentation and provides a potential method for enhancing the mango wine aroma profile by fermentation with the inclusion of pulp, which mimics the maceration process of red grape wine fermentation.

The aim of this study was to compare the fermentation dynamics and chemical profile of mango wine fermented with uncentrifuged (with pulp included) and centrifuged (with pulp removed) juices. Terpenes are significant contributors to the unique mango aroma (Macleod et al., 1988; Pino et al., 2005; Pino and Mesa, 2006), but are largely metabolised upon mango wine fermentation (Li et al., 2011, 2012). The hypothesis of the present study was that mango pulp contained more aroma compounds bound as glycosides than the centrifuged mango juice, and that wine yeast would release these bound aroma compounds from the glycosides present in the pulp, which would also compensate for the loss of the terpenes during fermentation. The ultimate aim was to enable the intensification and diversification of the mango wine flavour so as to achieve unique mango wine style and distinction.

\section{MATERIALS AND METHODS}

\section{Yeast strain and media}

Saccharomyces cerevisiae MERIT.ferm (Chr.-Han., Horsholm, Denmark) was used in this study because of its ability to produce more branched-chain alcohols and esters in 'Chok Anan' mango wine ( $\mathrm{Li}$ et al., 2011). The yeast was maintained in nutrient broth (pH 5.0) consisting of $2 \%(\mathrm{w} / \mathrm{v})$ glucose, $0.25 \%(\mathrm{w} / \mathrm{v})$ yeast extract, $0.25 \%(\mathrm{w} / \mathrm{v})$ bacteriological peptone and $0.25 \%(\mathrm{w} / \mathrm{v})$ malt extract and incubated at $25^{\circ} \mathrm{C}$ for up to $48 \mathrm{~h}$. The yeast was stored at $-80^{\circ} \mathrm{C}$ with $20 \%$ glycerol before use. Potato dextrose agar (PDA) (39 g/L, Oxoid, Basingstoke, Hampshire, England) was used for plating to monitor the growth of the Saccharomyces yeast at indicated time points.

\section{Preparation of centrifuged and uncentrifuged mango juices}

'Chok Anan' mangoes from Malaysia were purchased from a local market in Singapore and stored at $25^{\circ} \mathrm{C}$ until fully ripened before use. The preparation of mango juice was done in accordance with the method of Li et al. (2011), with modifications. The ripened mangoes were juiced and divided into two lots. The first lot was centrifuged at 21000 rpm (41 $415 \mathrm{~g}$, Beckman Centrifuge, MA, USA) and $4^{\circ} \mathrm{C}$ for $10 \mathrm{~min}$ to remove the pulp, and the centrifuged juice (supernatant) was stored at $-50^{\circ} \mathrm{C}$ until further use. The second lot, containing the pulp, was stored directly at $-50^{\circ} \mathrm{C}$ without being subjected to centrifugation (uncentrifuged juice). The pre-culture medium was prepared using the centrifuged mango juice $\left(14.97^{\circ} \mathrm{Brix}\right.$, containing $31 \mathrm{~g} / \mathrm{L}$ of fructose, $15 \mathrm{~g} / \mathrm{L}$ of glucose and $76 \mathrm{~g} / \mathrm{L}$ of sucrose, $\mathrm{pH} 4.76$ ), and the juice was heat-treated using a Hirayama HG- 80 autoclave (Hirayama, Saitama, Japan) at $100^{\circ} \mathrm{C}$ for $3 \mathrm{~min}$ and cooled to room temperature before use. The medium was inoculated with $10 \%(\mathrm{v} / \mathrm{v})$ of the yeast strain and incubated for $48 \mathrm{~h}$ at $25^{\circ} \mathrm{C}$ until yeasts grew to at least $10^{7} \mathrm{cfu} / \mathrm{mL}$. The centrifuged and uncentrifuged mango juices ( $\mathrm{pH}$ adjusted to $3.5 \mathrm{with} 50 \% \mathrm{w} / \mathrm{v}$ food grade d/1-malic acid from Suntop Ltd, Singapore) used for fermentation were treated with sulphur dioxide in the form of $\mathrm{K}_{2} \mathrm{~S}_{2} \mathrm{O}_{5}$, potassium metabisulphite (The Goodlife Homebrew Centre, Norfolk, England) at 100 ppm ( $\mathrm{K}_{2} \mathrm{~S}_{2} \mathrm{O}_{5}$ was added just before heating), then heated at $60^{\circ} \mathrm{C}$ for 15 minutes and cooled to room temperature before use. The reason for the addition of sulphur dioxide was to prevent polyphenol oxidase from causing browning of the mango juice.

\section{Fermentation}

Mango juice fermentations were carried out in triplicate in $500 \mathrm{~mL}$ sterile Erlenmeyer conical flasks, with each flask containing $450 \mathrm{~mL}$ of centrifuged or uncentrifuged mango juice. All samples were inoculated with $1 \%(\mathrm{v} / \mathrm{v})$ pre-culture of $S$. cerevisiae MERIT.ferm, and the fermentations were conducted statically at $20^{\circ} \mathrm{C}$ for 10 days. Sampling was done during fermentation (Day 0, 2, 4, 7, 10).

\section{Sample analysis}

Both $\mathrm{pH}$ and total soluble solids ( ${ }^{\circ}$ Brix) were measured in duplicate at the indicated time points by a $\mathrm{pH}$ meter and a refractometer respectively.

The concentration of sugars and organic acids was analysed in duplicate by Shimadzu ultrafast liquid chromatography (UFLC). Cell-free wine samples were obtained by centrifugation and filtration through a $0.2 \mu \mathrm{m}$ regenerated cellulose filter membrane (Sartorius Stedium Biotech, Geottingen, Germany). The column used for sugar analysis was a Zorbax carbohydrate column $(4.6 \times 150 \mathrm{~mm}$, 5 -micron, Agilent, Santa Clara, CA, USA). The column was connected to an evaporative light scattering detector $\left(40^{\circ} \mathrm{C}\right.$, $350 \mathrm{Kpa} \mathrm{N}$, Gain 5). Organic acids were determined with a Supelcogel C-610H column (Supelco Bellefonte, PA, USA) connected to a photodiode array detector at UV 210 $\mathrm{nm}$. Other UFLC running conditions were as described in $\mathrm{Li}$ et al. (2012).

The volatile compounds were measured in duplicate using a headspace (HS) solid-phase microextraction (SPME) method, coupled with a gas chromatography (GC)-mass spectrometer (MS) and flame ionisation detector (FID) (HS-SPME-GC-MS/FID). A carboxen/PDMS fibre $(85 \mu \mathrm{m})$ (Supelco, Sigma-Aldrich, Barcelona, Spain) was used for 
the extraction of volatiles. Sample volume was $5 \mathrm{~mL}$ and it was subjected to extraction by HS-SPME at $60^{\circ} \mathrm{C}$ for 40 min under $250 \mathrm{rpm}$ agitation. The fibre was then desorbed at $250^{\circ} \mathrm{C}$ for $3 \mathrm{~min}$, before the sample was injected into the Agilent 7890A GC (Santa Clara, CA, USA), which was coupled to the FID and Agilent 5975C triple-axis MS. The capillary column for separation was an Agilent DB-FFAP of $60 \mathrm{~m} \times 0.25 \mathrm{~mm}$ I.D., coated with $0.25 \mu \mathrm{m}$ film thickness of polyethylene glycol modified with nitroterephthalic acid. For quantitative analysis of the samples, major volatiles (major peaks in the FID chromatogram) were quantified by comparison with available external standards. The method was modified from Chen et al. (2006) and validated. The other details of the HS-SPME-GC-MS/FID are given in Li et al. (2012). All samples were clarified by centrifugation before GC analysis. Odour activity values of these quantified volatiles were calculated according to their established threshold levels in the literature (Guth, 1997; Lambrechts \& Pretorius, 2000; Yamamoto et al., 2004; Zemni et al., 2007; Bartowsky \& Pretorius, 2008).

\section{Statistical analysis}

The statistical differences of the chemical composition of mango wine fermented from centrifuged and uncentrifuged juices (before and after fermentation) were evaluated by oneway analysis of variance (ANOVA) or Student's T-test. All tests of significance were conducted at a probability level of $P<0.05$. The means and standard deviations were obtained from triplicate fermentation samples.

\section{RESULTS AND DISCUSSION}

\section{Yeast growth, ${ }^{\circ} \mathrm{Brix}$ and $\mathrm{pH}$ changes}

The growth dynamics of $S$. cerevisiae MERIT.ferm in centrifuged and uncentrifuged juices (corresponding to non-macerated wine and macerated wine respectively) were similar, although with some differences during the first four days (Fig. 1). The viable cell count in the non-macerated wine increased more rapidly and reached a maximum of $1.26 \times 10^{8} \mathrm{cfu} / \mathrm{mL}$ on day 2 , followed by a stationary phase until day 10. Rapid cell growth in the macerated wine was observed only after day 2 , and reached a maximum of 8.35 $\times 10^{7} \mathrm{cfu} / \mathrm{mL}$ on day 10 . The final viable cell count in the macerated wine was lower than that in the non-macerated wine (Table 1).

The unfermented centrifuged juice had a total soluble solid content of $14.79{ }^{\circ}$ Brix (Table 1). The total soluble solid content of the unfermented, uncentrifuged juice was determined to be $15.32{ }^{\circ}$ Brix. A rapid reduction in ${ }^{\circ}$ Brix was observed from day 0 in the non-macerated wine, whereas this rapid reduction in ${ }^{\circ}$ Brix occurred only after day 2 in the macerated wine, being consistent with yeast growth dynamics. The total soluble solids reached a final value of around $5.45{ }^{\circ}$ Brix for the non-macerated wine and 6.00 ${ }^{\circ}$ Brix for the macerated wine. The lower yeast cell count in the macerated wine could be due to the more viscous nature of the uncentrifuged juice. A higher viscosity of the fermentation medium could result in less oxygen or nutrients being available, which may affect cell growth (Vaudano et al., 2004). The lower yeast count in the macerated wine could also be due to inhibitory substances contained in the uncentrifuged juice, or produced by yeast from substrates in the pulp, but this warrants further study. The $\mathrm{pH}$ in the nonmacerated wine rose slightly, from 3.51 to 3.58 , but the $\mathrm{pH}$ of the macerated wine increased more significantly, from 3.49 to 3.71 , which could be ascribed to the differences in organic acid transformation in the uncentrifuged and centrifuged mango juices discussed below.

\section{Sugar and organic acid contents before and after fermentation}

The total sugar content of the centrifuged and uncentrifuged juices was $12.25 \%(\mathrm{w} / \mathrm{v})$ and $12.46 \%(\mathrm{w} / \mathrm{v})$ respectively (Table 1). The sugars were almost exhausted after fermentation. Fermentation was considered complete by day 10 , with a residual amount of 0.41 to $0.47 \mathrm{~g} / \mathrm{L}$ of glucose and sucrose. The content of the remaining fructose at day 10 was $0.18 \mathrm{~g} / \mathrm{L}$ in the non-macerated wine and not detectable in the macerated wine.

The change in organic acids is shown in Table 1. Citric acid decreased significantly in the macerated wine. Tartaric acid decreased from about $0.5 \mathrm{~g} / \mathrm{L}$ to about $0.2 \mathrm{~g} / \mathrm{L}$ in both wines, likely due to precipitation of tartrate salts (e.g. potassium tartrate or calcium tartrate). Malic acid was the major organic acid in both the centrifuged and uncentrifuged juices (originally about $3 \mathrm{~g} / \mathrm{L}$ ), and increased to concentrations of 6.9 and $7.2 \mathrm{~g} / \mathrm{L}$ after acidification with $\mathrm{d} / \mathrm{l}$-malic acid in the
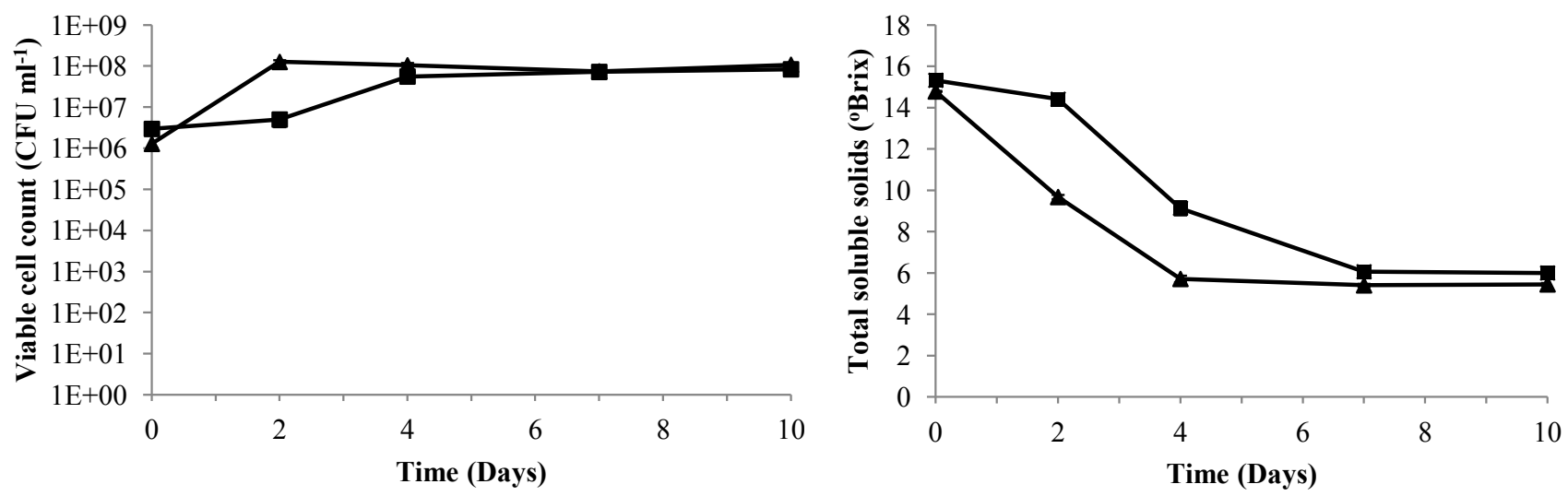

FIGURE 1

Yeast growth and changes in ${ }^{\circ}$ Brix for mango wine fermentation with centrifuged $(\boldsymbol{\Delta})$ and uncentrifuged juices $(\boldsymbol{\square})$. 
TABLE 1

Physicochemical properties, alcohol, organic acid and sugar concentrations of mango wines with and without pulp.

\begin{tabular}{|c|c|c|c|c|}
\hline \multirow[t]{2}{*}{ Fermentation medium } & \multicolumn{2}{|l|}{ Day 0} & \multicolumn{2}{|l|}{ Day 10} \\
\hline & Centrifuged juice & Uncentrifuged juice & Non-macerated wine & Macerated wine \\
\hline \multicolumn{5}{|l|}{ Physicochemical properties } \\
\hline $\mathrm{pH}$ & $3.51 \pm 0.02^{a}$ & $3.49 \pm 0.03^{a}$ & $3.58 \pm 0.00^{b}$ & $3.71 \pm 0.01^{c}$ \\
\hline Total soluble solids ( $\left.{ }^{\circ} \mathrm{Brix}\right)$ & $14.79 \pm 0.03^{a}$ & $15.32 \pm 0.09^{b}$ & $5.45 \pm 0.07^{c}$ & $6.00 \pm 0.20^{d}$ \\
\hline Cell count $\left(10^{6} \mathrm{cfu} / \mathrm{mL}\right)$ & $1.28 \pm 0.26^{a}$ & $2.96 \pm 0.84^{a}$ & $107.8 \pm 2.8^{b}$ & $83.50 \pm 8.88^{c}$ \\
\hline \multicolumn{5}{|l|}{ Alcohol } \\
\hline Ethanol $(\% \mathrm{v} / \mathrm{v})$ & $0.13 \pm 0.03^{a}$ & $0.15 \pm 0.01^{a}$ & $7.69 \pm 0.06^{b}$ & $7.99 \pm 1.62^{b}$ \\
\hline Glycerol (g/L) & N.D. & N.D. & $5.43 \pm 0.11^{a}$ & $6.81 \pm 0.14^{b}$ \\
\hline \multicolumn{5}{|l|}{ Reducing sugars (g/L) } \\
\hline Fructose & $31.2 \pm 0.8^{a}$ & $34.7 \pm 5.5^{a}$ & $0.18 \pm 0.00^{b}$ & N.D. \\
\hline Glucose & $15.7 \pm 0.5^{a}$ & $16.6 \pm 0.7^{a}$ & $0.42 \pm 0.03^{b}$ & $0.41 \pm 0.01^{b}$ \\
\hline Sucrose & $75.6 \pm 2.9^{a}$ & $73.3 \pm 3.3^{a}$ & $0.43 \pm 0.03^{b}$ & $0.47 \pm 0.03^{b}$ \\
\hline \multicolumn{5}{|l|}{ Organic acid $(g / L)$} \\
\hline Citric & $1.93 \pm 0.11^{a b}$ & $2.01 \pm 0.03^{a}$ & $1.82 \pm 0.07^{a b}$ & $1.74 \pm 0.09^{b}$ \\
\hline Tartaric & $0.44 \pm 0.09^{a}$ & $0.53 \pm 0.05^{a}$ & $0.23 \pm 0.01^{b}$ & $0.26 \pm 0.14^{b}$ \\
\hline Malic & $6.92 \pm 0.51^{a}$ & $7.23 \pm 0.03^{a}$ & $3.82 \pm 0.05^{b}$ & $3.31 \pm 0.21^{b}$ \\
\hline Pyruvic & N.D. & N.D. & $0.11 \pm 0.00^{a}$ & $0.11 \pm 0.01^{a}$ \\
\hline Succinic & $1.02 \pm 0.08^{a}$ & $1.15 \pm 0.07^{a}$ & $0.98 \pm 0.03^{a}$ & $1.07 \pm 0.05^{a}$ \\
\hline
\end{tabular}

abcd ANOVA $(\mathrm{n}=6)$ at $95 \%$ confidence level with same letter indicating no significant difference (using ANOVA)

*N.D.: not detected

two juices respectively. Malic acid decreased significantly to 3.8 and $3.3 \mathrm{~g} / \mathrm{L}$ respectively. As $S$. cerevisiae is known to be inefficient in metabolising malic acid, the decrease in malic acid concentration could be due mainly to the passive diffusion of d-malic acid into the yeast cells, which has been demonstrated in another study (Coloretti et al., 2002). Also, 1-malic acid could be partially metabolised by $S$. cerevisiae (Rankine, 1966; Redzepovic et al., 2003). The decrease in malic acid was not likely due to malolactic fermentation, as no lactic acid was detected. There was no significant change in succinic acid before and after fermentation, or between the centrifuged and uncentrifuged juices. Pyruvic acid was not detected at day 0 and was produced in low concentrations of around $0.1 \mathrm{~g} / \mathrm{L}$ after fermentation, with no significant difference between the centrifuged and uncentrifuged juices.

\section{Ethanol and glycerol contents of mango wine}

The ethanol content of the mango wine that was produced was $7.69 \%(\mathrm{v} / \mathrm{v})$ for the non-macerated wine and $7.99 \%$ $(\mathrm{v} / \mathrm{v})$ for the macerated wine (Table 1). These figures are comparable to those in other studies on mango wine, which reported ethanol contents of between 6.5 and $10.7 \%$ (v/v) (Reddy \& Reddy, 2005; Reddy et al., 2010; Pino \& Queris 2011). Glycerol is a simple alcohol and a by-product formed by $S$. cerevisiae in order to maintain the cytosolic redox balance, especially under anaerobic conditions (Wang et al., 2001). It is known to impart a sweet taste to wines and contributes to mouthfeel (Suárez-Lepe \& Morata, 2012). Although no glycerol was detected at day 0 , its concentration increased significantly to $5.4 \mathrm{~g} / \mathrm{L}$ for the non-macerated wine and $6.8 \mathrm{~g} / \mathrm{L}$ for the macerated wine. The higher concentration of glycerol in the macerated wine was probably due to the higher osmotic pressure in the uncentrifuged juice (Scanes et al., 1998) and the resultant impact on redox imbalance. These concentrations were consistent with the common contents of glycerol in wines of between 5 and $8 \mathrm{~g} / \mathrm{L}$ (Scanes et al., 1998).

\section{Volatile profile of mango juice and wine Major volatiles in juice}

The dominant class of compounds in the mango juice belonged to the terpene group, in which the most abundant compound was $\alpha$-terpinolene. This was consistent with previous studies that showed that terpene hydrocarbons were the major volatiles of fresh mango juice, with cultivars such as Kaew, Obispo, Corazon, Huovo de Toro and Chok Anan containing high $\alpha$-terpinolene contents (Macleod et al., 1988; Pino \& Mesa, 2006; Li et al., 2011). Alcohols were the second dominant class of compounds, and (Z)-3-hexenol was the major one contributing a green and grassy odour (Pino et al., 2005; Li et al., 2011). However, ethanol was low in concentration in the fresh mango juice.

\section{Evolution of terpenes}

Terpenes decreased significantly in the first four days of fermentation in both the non-macerated and the macerated wine (Fig. 2). This was observed for all monoterpenes, including $\alpha$-terpinolene and limonene. This decrease in terpene content has also been reported in litchi wine $(\mathrm{Wu}$ et al., 2011). The loss of terpenes could be due to the biotransformation and biodegradation of terpenes by yeast (Marais, 1984; Misra et al., 1996). For example, under the initial aerobic conditions of fermentation, $S$. cerevisiae was able to utilise terpenes as a biosynthetic intermediate 

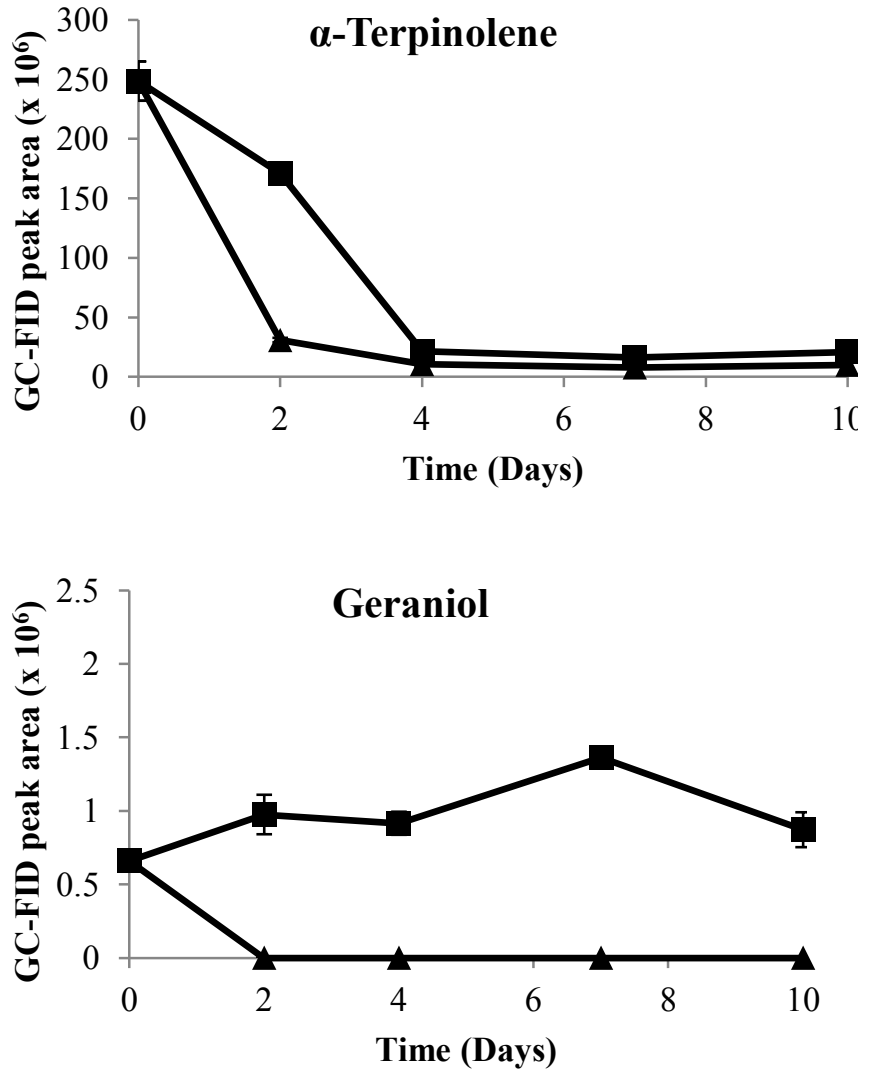
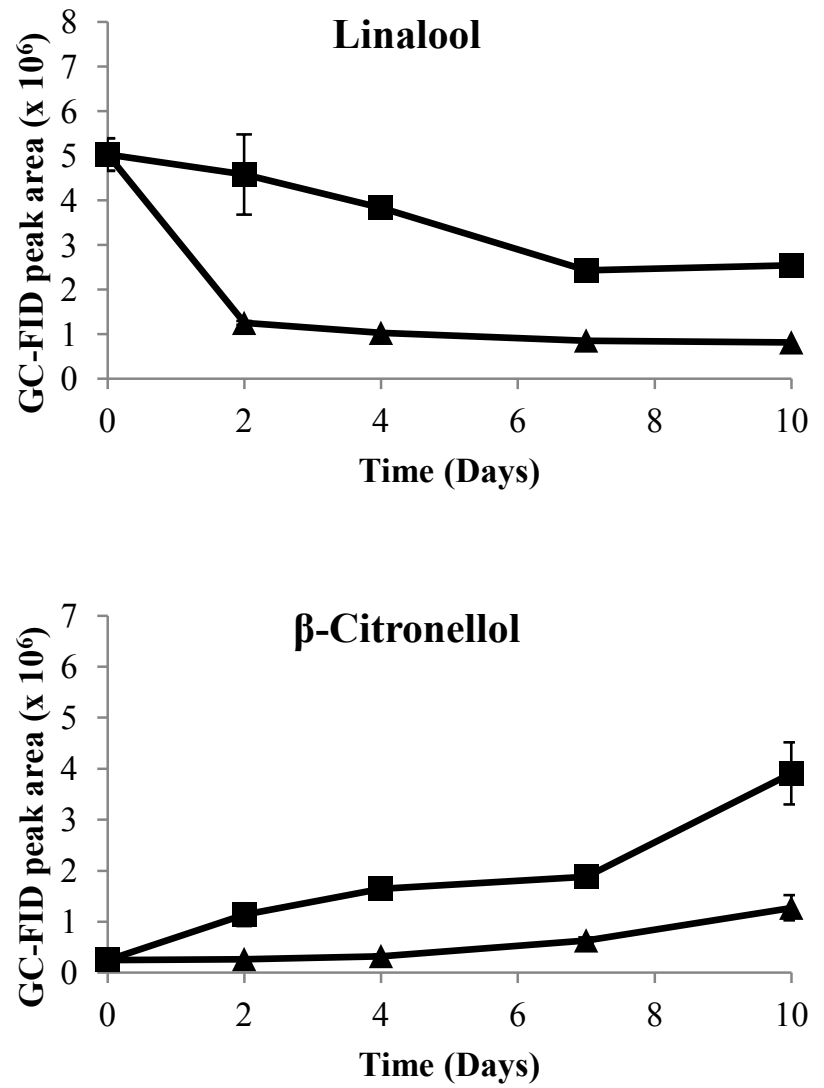

FIGURE 2

Evolution trends of terpenes and terpene alcohols during mango wine fermentation with centrifuged $(\boldsymbol{\Delta})$ and uncentrifuged juices ( $\mathbf{\square})$.

for sterol synthesis (Zea et al., 1995). Terpenes could also be volatilised and drawn off by the $\mathrm{CO}_{2}$ produced, and lost during the metabolite exchange taking place between the medium and the atmosphere (Arévalo Villena et al., 2006). Generally, the decrease in terpenes in the macerated wine was less compared to that in the non-macerated wine, and was at slightly higher levels at day 10 (Fig. 2). The concentration of $\alpha$-terpinolene was about ten times higher in the macerated wine than in the non-macerated wine (Table 2). This could be due to more terpenes being extracted into wine from the pulpy materials by the ethanol produced and/or due to the release of glycosidically-bound terpenes in the mango pulp through the $\beta$-glucosidase activity of $S$. cerevisiae (Mateo \& Stefano, 1997). The decrease in terpene concentration would cause the loss of the original mango aroma, as terpenes quantitatively represent a large share of mango volatiles and contain some of the main contributors to mango aroma (Pino et al., 2005). From our result, the inclusion of pulp could, to some extent, help compensate for terpene losses.

Terpene alcohols (terpenols) have previously been reported to be present as free volatiles in some mango varieties (Ollé et al., 1998). Linalool, geraniol, $\beta$-citronellol, nerol and $\alpha$-terpineol were identified in 'Chok Anan' mango juice (data not shown), with $\beta$-citronellol and geraniol being the major ones. These terpenols are also known to be important to the aroma of wine from grape varieties of Muscat, Riesling and other aromatic grape varieties (Marais, 1984; Swiegers et al., 2005). The biotransformation of terpenols by $S$. cerevisiae has been characterised in different
Muscat wines and beers (Marais 1984; King \& Dickinson, 2000; Takoi et al., 2010; Gamero et al., 2011). It was found that geraniol can be converted into $\beta$-citronellol and other terpenols by yeast metabolism, while nerol and linalool can also be converted into $\alpha$-terpineol, terpinolene and limonene. The production of terpenols can also occur and this has previously been hypothesised to be a result of de novo synthesis by $S$. cerevisiae through an alternative pathway involving the metabolism of leucine (Carrau et al., 2005). In the current study, linalool decreased in both wines throughout the fermentation (Fig. 2), but the rate of decrease was higher in the non-macerated wine. $\beta$-Citronellol increased throughout fermentation in both the non-macerated and the macerated wine, but the rate of increase was higher in the latter (Fig. 2). Geraniol could have been converted into $\beta$-citronellol, resulting in its depletion in the non-macerated wine at day 2 of fermentation (Fig. 2).

An opposite trend was observed for geraniol in the macerated wine, where it initially increased, followed by a slight decrease after day 7 , and the final amount of geraniol in the macerated wine was higher than its initial concentration at day 0 (Fig. 2). In addition to yeast transformation, $\beta$-glucosidase activity is another factor that could contribute to the changes in terpene and terpenol contents. Previous studies on mango showed that terpenols also existed as bound fractions in mango (Drider et al., 1994; Ollé et al., 1998). Furthermore, $\beta$-glucosidase activity is also known to be present in $S$. cerevisiae, with higher activities in the early stages of fermentation (Mateo \& Stefano, 1997). 
TABLE 2

Volatiles (mg/L) and their odour activity values (OAVs) of non-macerated and macerated mango wines.

\begin{tabular}{|c|c|c|c|c|c|c|c|c|}
\hline Group & Compound & $\mathbf{L R I}^{\mathbf{a}}$ & $\begin{array}{c}\text { Non-macerated } \\
\text { wine }(\mathrm{mg} / \mathrm{L})\end{array}$ & $\mathbf{O A V} \mathbf{V}^{\mathbf{b}}$ & $\begin{array}{c}\text { Macerated } \\
\text { wine }(\mathrm{mg} / \mathrm{L})\end{array}$ & OAV & $\begin{array}{c}\text { Odour } \\
\text { threshold } \\
(\mathrm{mg} / \mathrm{L})\end{array}$ & Odour descriptors \\
\hline \multirow[t]{5}{*}{ Acid } & Acetic acid & 1408 & $61.61 \pm 5.65^{a}$ & 0.31 & $165 \pm 12.35^{b}$ & 0.82 & $200^{\mathrm{c}}$ & Acidic, vinegar \\
\hline & Hexanoic acid & 1780 & N.D. & 0.00 & $0.36 \pm 0.09^{a}$ & 1.20 & $0.3^{\mathrm{c}}$ & Sour, fatty, sweaty \\
\hline & Octanoic acid & 1990 & $6.04 \pm 0.53^{a}$ & 0.69 & $1.75 \pm 0.29^{b}$ & 0.20 & $8.8^{\mathrm{d}}$ & Fatty, soapy, sour \\
\hline & Decanoic acid & 2188 & $1.09 \pm 0.21^{a}$ & 0.07 & $0.24 \pm 0.02^{b}$ & 0.02 & $15^{\mathrm{c}}$ & Fatty, rancid, sour \\
\hline & Dodecanoic acid & 2393 & $0.736 \pm 0.099^{a}$ & 0.07 & $0.13 \pm 0.01^{b}$ & 0.01 & $10^{\mathrm{e}}$ & Coconut, fatty \\
\hline \multirow[t]{5}{*}{ Alcohol } & Isobutyl alcohol & 981 & $34.1 \pm 6.1^{a}$ & 0.85 & $65.7 \pm 11.2^{b}$ & 1.6 & $40^{c}$ & Fruity, wine-like \\
\hline & Active amyl alcohol & 1173 & $9.63 \pm 0.80^{a}$ & 0.15 & $17.97 \pm 2.33^{b}$ & 0.28 & $65^{\mathrm{f}}$ & Winey, fruity \\
\hline & Isoamyl alcohol & 1173 & $171 \pm 10.08^{a}$ & 5.7 & $182 \pm 6.29^{a}$ & 6.07 & $30^{\mathrm{c}}$ & Alcoholic, banana \\
\hline & (Z)-3-Hexenol & 1350 & $0.599 \pm 0.074^{a}$ & 1.50 & $0.90 \pm 0.08^{b}$ & 2.26 & $0.4^{\mathrm{c}}$ & Green, leafy \\
\hline & 2-Phenylethyl alcohol & 1944 & $72.78 \pm 7.97^{a}$ & 7.28 & $86.90 \pm 12.50^{a}$ & 8.69 & $10^{\mathrm{c}}$ & Sweet, rose, floral \\
\hline \multirow[t]{10}{*}{ Ester } & Ethyl acetate & 858 & $0.13 \pm 0.02^{a}$ & 0.02 & $0.17 \pm 0.02^{a}$ & 0.02 & $7.5^{\mathrm{c}}$ & Ethereal, fruity, sweet \\
\hline & Isobutyl acetate & 979 & $0.066 \pm 0.008^{a}$ & 0.04 & $0.10 \pm 0.02^{b}$ & 0.06 & $1.6^{\mathrm{d}}$ & Sweet, fruity, apple \\
\hline & Isoamyl acetate & 1061 & $0.648 \pm 0.120^{a}$ & 216 & $1.24 \pm 0.01^{b}$ & 414 & $0.003^{\mathrm{c}}$ & Fruity, banana \\
\hline & Ethyl hexanoate & 1158 & $0.338 \pm 0.041^{a}$ & 67.6 & $0.18 \pm 0.03^{b}$ & 36.5 & $0.005^{\mathrm{c}}$ & Banana, fruity, floral \\
\hline & (Z)-3-Hexenyl acetate & 1206 & $0.044 \pm 0.001^{a}$ & 5.46 & $0.046 \pm 0.002^{a}$ & 5.80 & $0.008^{\mathrm{e}}$ & Fresh, green, fruity \\
\hline & Ethyl octanoate & 1374 & $4.25 \pm 0.73^{a}$ & 2123 & $1.12 \pm 0.02^{b}$ & 559 & $0.002^{\mathrm{c}}$ & Waxy, pineapple, fruity \\
\hline & Ethyl decanoate & 1575 & $15.09 \pm 1.87^{a}$ & 75.45 & $2.09 \pm 0.44^{b}$ & 10.44 & $0.2^{\mathrm{d}}$ & Waxy, sweet, apple \\
\hline & Citronellyl acetate & 1595 & $0.024 \pm 0.001^{\mathrm{a}}$ & 0.10 & N.D. & 0.00 & $0.25^{\mathrm{g}}$ & Floral, green, fruity, citrus \\
\hline & 2-Phenylethyl acetate & 1773 & $2.38 \pm 0.54^{\mathrm{a}}$ & 9.52 & $2.46 \pm 0.31^{\mathrm{a}}$ & 9.84 & $0.25^{\mathrm{c}}$ & Floral, rose, sweet \\
\hline & Ethyl dodecanoate & 1785 & $6.22 \pm 0.39^{\mathrm{a}}$ & 5.19 & $0.69 \pm 0.10^{\mathrm{b}}$ & 0.58 & $1.2^{\mathrm{d}}$ & Soapy, waxy, floral \\
\hline \multirow[t]{3}{*}{ Terpene } & $\alpha$-Terpinolene & 1264 & $0.03 \pm 0.00^{\mathrm{a}}$ & - & $0.39 \pm 0.04^{b}$ & - & Not applicable & Woody, citrus, pine, green \\
\hline & $\beta$-Citronellol & 1770 & $0.008 \pm 0.003^{a}$ & 0.08 & $0.034 \pm 0.001^{b}$ & 0.34 & $0.1^{\mathrm{c}}$ & Rose, citrus, green \\
\hline & Geraniol & 1861 & N.D. & 0 & $0.005 \pm 0.000^{a}$ & 0.17 & $0.03^{\mathrm{c}}$ & Sweet, floral, fruity, citrus \\
\hline
\end{tabular}

${ }^{a b} \operatorname{ANOVA}(\mathrm{n}=6)$ at $95 \%$ confidence level with same letter indicating no significant difference (using T-test).

*N.D.: not detected, \pm standard deviation

${ }^{\mathrm{a}}$ Linear retention index

${ }^{b}$ Odour activity values (OAV) were calculated by dividing concentration by the odour threshold value of the compound.

'The odour threshold obtained from Guth (1997).

dThe odour threshold obtained from Bartowsky and Pretorius (2008).

${ }^{\mathrm{e}}$ The odour threshold obtained from Lambrechts and Pretorius (2000).

The odour threshold obtained from Zemni et al. (2007).

'The odour threshold obtained from Yamamoto et al. (2004).

Thus, it could be that the higher geraniol and $\beta$-citronellol concentrations in the macerated wine (Fig. 2, Table 2) were also due to more terpenol-containing glycosides in the mango pulp being hydrolysed by the $\beta$-glucosidase from yeast. More geraniol could lead to more $\beta$-citronellol production, and the reduction in geraniol correlated with the increase in $\beta$-citronellol production (Fig. 2). The concentrations of $\beta$-citronellol and geraniol were below their threshold (Table 2), but they may contribute to the wine bouquet synergistically (Styger et al., 2011). Other glycosidicallybound aroma compounds in mango, such as geranial and 1,8-menthadien-4-ol, were also increased (data not shown), being consistent with the result in Lalel et al. (2003).

\section{Evolution of alcohols}

Ethanol, isobutyl alcohol (2-methyl-1-propanol), isoamyl alcohol (3-methyl-1-butanol), active amyl alcohol (2-methyl- 1-butanol) and 2-phenylethyl alcohol were identified as the major alcohols present in the mango wines. Their dynamic changes were similar in both the centrifuged and uncentrifuged juice fermentations, with rapid formation of these compounds initially, followed by a plateau at around day 4 (Fig. 3). This trend was similar to that found in our previous study (Li et al., 2011). Isobutyl alcohol, isoamyl alcohol, active amyl alcohol and 2-phenylethyl alcohol are also classified as higher alcohols or fusel alcohols, which are known to have a significant impact on the character of wine. These alcohols are produced mainly by yeasts during alcoholic fermentation. This takes place through the Ehrlich pathway, involving branched-chain and aromatic amino acids (Lambrechts \& Pretorius, 2000). Amino acids such as l-valine, 1-isoleucine, 1-leucine and 1-phenylalanine are known to be responsible for the synthesis of isoamyl alcohol, active amyl alcohol, isobutyl alcohol and 2-phenylethyl alcohol (Styger 

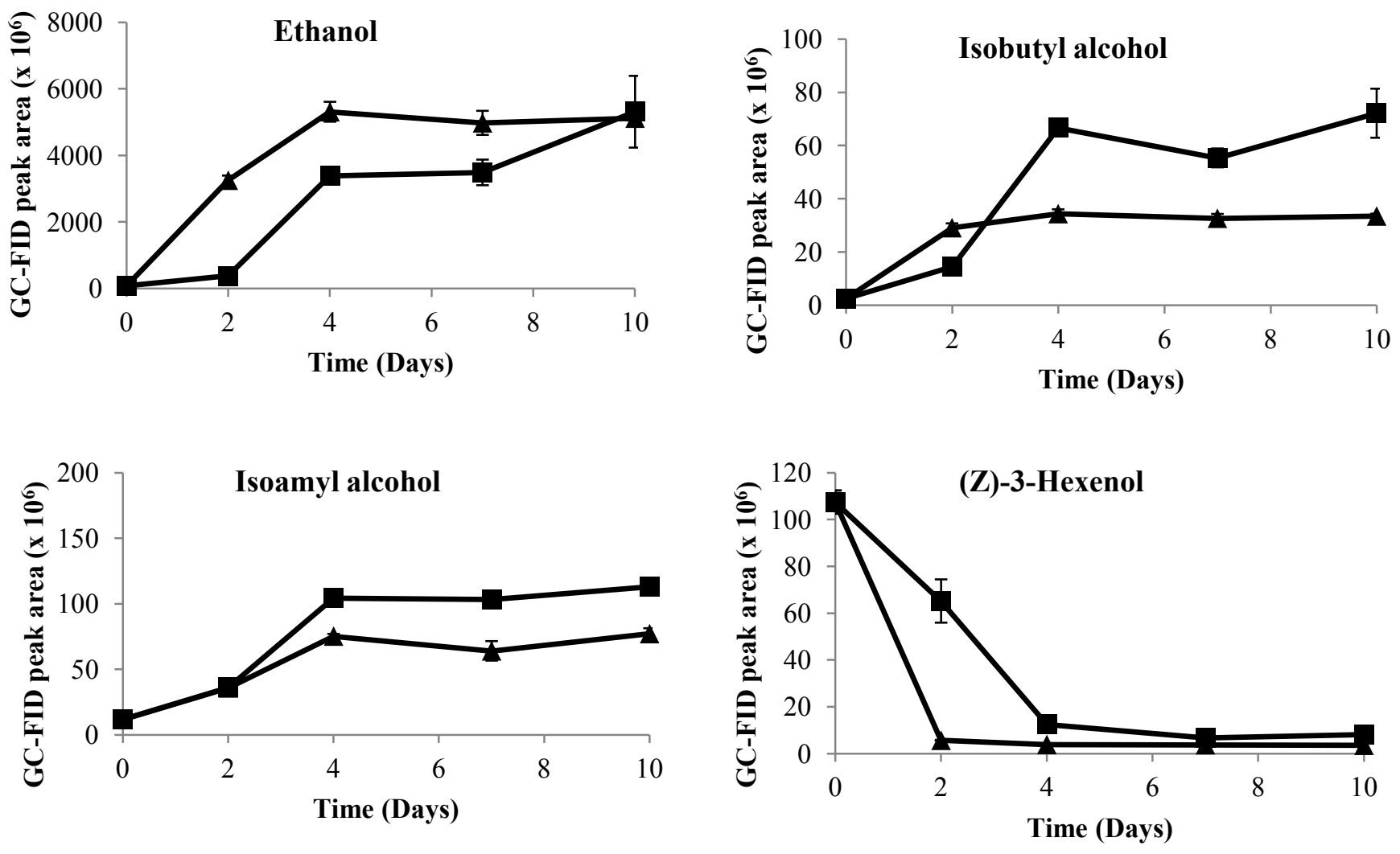

FIGURE 3

Evolution trends of alcohols during mango wine fermentation with centrifuged $(\boldsymbol{\Delta})$ and uncentrifuged juices $(\boldsymbol{\square})$.

et al., 2011). The macerated wine consistently showed a higher concentration of the major higher alcohols towards day 10 (Fig. 3). While various fermentation conditions, such as yeast growth and fermentation temperature, are also known to affect the production of higher alcohols, the amino acid content is still the major influential factor (Lambrechts \& Pretorius, 2000).

In contrast to the trend of higheralcohols, the concentration of (Z)-3-hexenol was drastically reduced (Fig. 3). (Z)-3Hexenol has not been reported as a fermentation product of yeast and might have been transformed to esters or reduced to 1-hexanol. 2-Phenylethyl alcohol, isoamyl alcohol and (Z)-3-hexenol were at levels higher than their threshold levels in both the non-macerated and macerated wines, and the isobutyl alcohol level was higher than its threshold in the macerated wine only (Table 2). Isoamyl alcohol is known to be a major constituent of mango wine and is responsible for the winey odour (Reddy et al., 2010). Isobutyl alcohol is responsible for the fruity and winey odours, whereas (Z)-3hexenol can contribute an intense green grassy odour. On the other hand, 2-phenylethyl alcohol is one of the few aromatic alcohols responsible for the rose and floral odours (Swiegers et al., 2005).

\section{Evolution of fatty acids}

The major volatile fatty acids in the mango wines were acetic, octanoic, decanoic and dodecanoic acids. The pattern of their dynamic changes was similar to that of alcohols (Fig. 4). Acetic acid was higher in the macerated wine $(165 \mathrm{mg} / \mathrm{L})$ than in the non-macerated wine $(61.61 \mathrm{mg} / \mathrm{L})$, whereas the non- macerated wine showed significantly higher concentrations of octanoic, decanoic and dodecanoic acids. Acetic acid fulfils important metabolic roles in yeast and can be produced in $S$. cerevisiae through the oxidation of acetaldehyde. The medium-chain volatile fatty acids are known as intermediates produced by yeasts in the biosynthesis of long-chain fatty acids, which are the essential precursors for lipid components in yeast (Lambrechts \& Pretorius, 2000). These compounds are commonly associated with soapy, rancid and fatty odours and could adversely affect the aroma of wine. On the other hand, acetic acid may impart a vinegar-like character to wine when present at high concentrations (Swiegers et al., 2005). The quantitative differences in fatty acids between the nonmacerated and macerated wines are shown in Table 2. All fatty acids (except for hexanoic acid) were at levels below their threshold levels. The reason for the differences in fatty acids between the non-macerated and macerated wines merits further research.

\section{Evolution of esters}

Esters are generally associated with fruity and floral aromas in wine (Lambrechts \& Pretorius, 2000). The dominant esters identified were ethyl esters of octanoate, decanoate, 9-decenoate and dodecanoate, as exemplified by ethyl octanoate and ethyl decanoate in Fig. 5. Ethyl esters increased rapidly initially and their concentrations were higher in the non-macerated wine. This trend was similar to that of the corresponding fatty acids (Fig. 4), and was also demonstrated in another study on the importance of the fatty acid precursor levels for the production of ethyl esters 

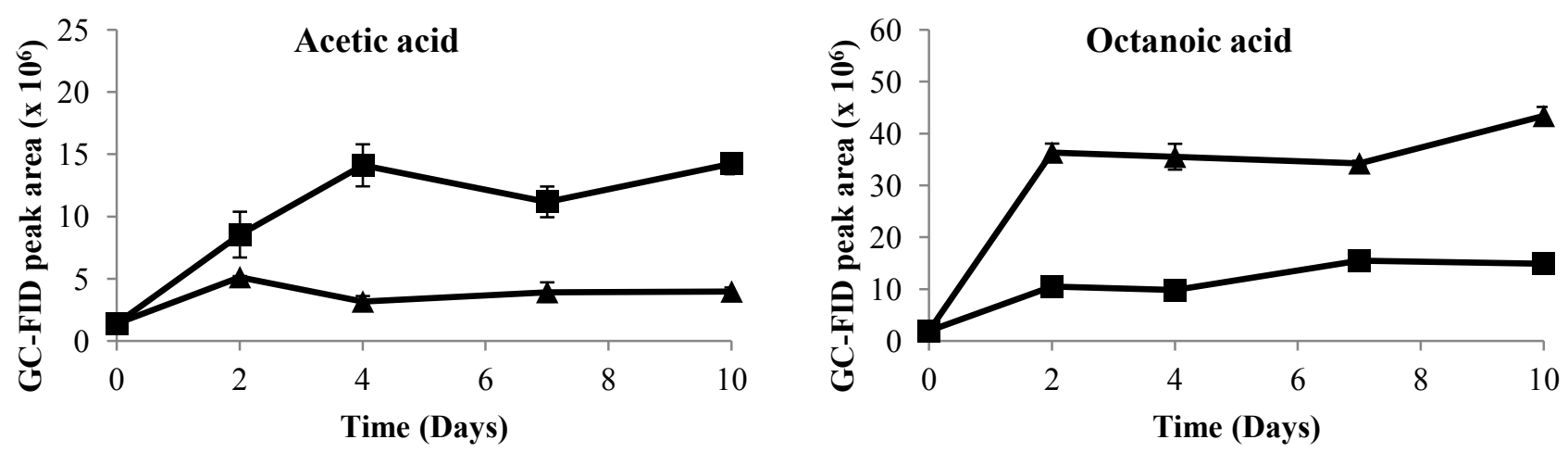

FIGURE 4

Evolution trends of volatile fatty acids during mango wine fermentation with centrifuged ( $\mathbf{\Delta})$ and uncentrifuged juices ( $\mathbf{\square})$.
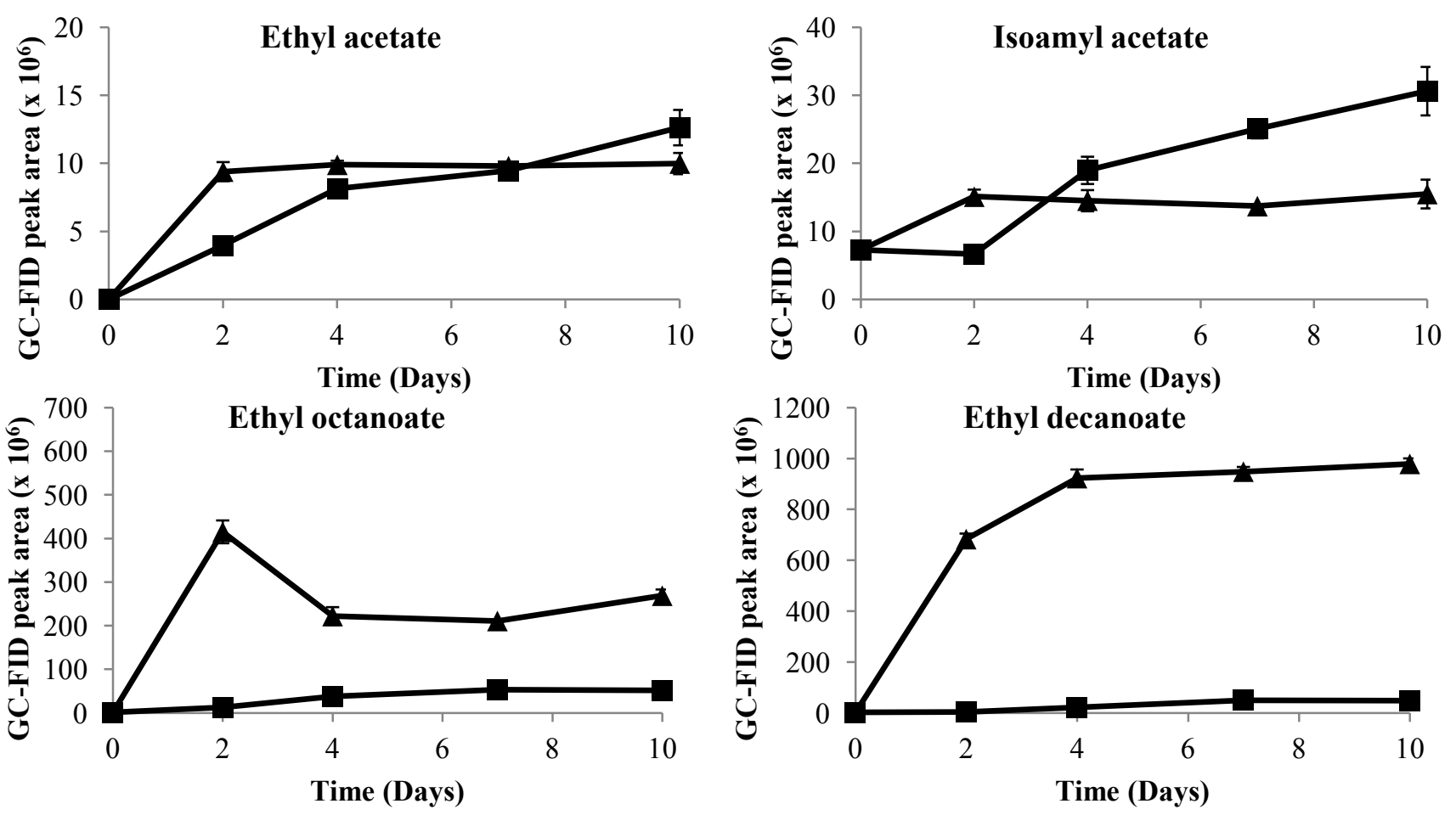

FIGURE 5

Evolution trends of esters during mango wine fermentation with centrifuged $(\boldsymbol{\Delta})$ and uncentrifuged juices $(\boldsymbol{\square})$.

(Saerens et al., 2008). The concentrations of ethyl esters were higher than their threshold levels (Table 2).

Acetate esters such as isoamyl acetate, isobutyl acetate, ethyl acetate and 2-phenylethyl acetate increased (exemplified by ethyl acetate and isoamyl acetate in Fig. 5). These esters are very important for wine fruitiness. Acetate esters were higher in the macerated wine (Table 2). Isoamyl acetate was found even at twice the concentration of that in the non-macerated wine at day 10 (Table 2). The higher concentrations of acetate esters in the macerated wine could be due to the higher concentrations of their respective higher alcohols in the same wine. This is because higher alcohols and acetyl-CoA are known as the main precursors for the formation of acetate esters (Suárez-Lepe \& Morata, 2012).

Other esters and ethers identified in the mango wine included citronellyl acetate, neryl acetate and geranyl ethyl ether, derived from the corresponding terpenols, demonstrating the further role of terpenols in mango wine aroma. These compounds have not yet been reported in other studies on mango wine. However, they have been suggested to be formed in litchi wine through the partial esterification of or etherification between the corresponding terpenols and acetyl-CoA (Wu et al., 2011).

\section{Evolution of sulphur compounds}

Two sulphur compounds, dihydro-2-methyl-3(2H)thiophenone and methionol, were also detected in both wines (data not shown). These compounds were not found in the centrifuged and uncentrifuged juices and most likely were produced by the yeast through the Ehrlich pathway during fermentation (Karagiannis \& Lanaridis, 1999). For instance, methionol is known to be produced from the catabolism of 
methionine and is responsible for potato, cooked cabbage and meat-like odours, while dihydro-2-methyl-3(2H)thiophenone is associated with blackberry odour (Mestres et al., 2000).

\section{CONCLUSIONS}

The mango wines fermented from centrifuged and uncentrifuged juices showed significant differences, especially in the volatile profile. The macerated wine contained more terpenes, terpenols, higher alcohols and fruity acetate esters than the non-macerated wine. The non-macerated wine possessed a higher concentration of medium-chain fatty acids and corresponding ethyl esters. The inclusion of pulp in mango wine fermentation, which is similar to the maceration process in red grape wine fermentation, was beneficial for retaining the original terpenic character of mango, and also improved other mango wine aroma characters (i.e. complexity) such as fruitiness.

\section{LITERATURE CITED}

Adedeji, J., Hartman, T.G., Lech, J. \& Ho, C.T., 1992. Characterization of glycosidically bound aroma compounds in the African Mango (Mangifera indica L.). J. Agric. Food Chem. 40, 659-661.

Arévalo-Villena, M., Díez-Pérez, J., Úbeda J.F., Navascués, E. \& Briones, A.I., 2006. A rapid method for quantifying aroma precursors: application to grape extract, musts and wines made from several varieties. Food Chem. 99, 183-190.

Bartowsky, E.J. \& Pretorius, I.S., 2008. Microbial formation and modification of flavor and off-flavor compounds in wine. In: Konig, H., Uden, G. \& Frohlich, J. (eds). Biology of microorganisms on grapes, in must and in wine. Springer-Verlag, Berlin. pp $215-217$.

Carrau, F.M., Medina, K., Boido, E., Farina, L., Gaggero, C., Dellacassa, E., Versini, G. \& Henschke, P.A., 2005. De novo synthesis of monoterpenes by Saccharomyces cerevisiae wine yeasts. FEMS Microbiol. Lett. 243, 107 115.

Chen, Y., Begnaud, F., Chaintreau, A. \& Pawliszyn, J., 2006. Quantification of perfume compounds in shampoo using solid-phase microextraction. Flavour Frag. J. 21, 822-832.

Coloretti, F., Zambonelli, C., Castellari, L., Tini, V. \& Rainieri, S., 2002. The effect of DL-malic acid on the metabolism of L-malic acid during wine alcoholic fermentation. Food Technol. Biotechnol. 40, 317-320.

Czyhrinciwk, N., 1966. The technology of passion fruit and mango wines. Am. J. Enol. Vitic. 17, 27-30.

Drider, D., Janbon, G., Chemardin, P., Arnaud, A. \& Galzy, P., 1994 Enzymatic hydrolysis of monoterpene glycosides of passion fruit and mango with a $\beta$-glucosidase from yeast. Bioresource Technol. 49, 243-246.

Gamero, A., Manzanares, P., Querol, A. \& Belloch, C., 2011. Monoterpene alcohols release and bioconversion by Saccharomyces species and hybrids. Int. J. Food Microbiol. 145, 92-97.

Guth, H., 1997. Quantitation and sensory studies of character impact odorants of different white wine varieties. J. Agric. Food Chem. 45, 3027 3032 .

Karagiannis, S. \& Lanaridis, P., 1999. The effect of various vinification parameters on the development of several volatile flavor compounds in Greek white wines of the cultivars Batiki and Muscat of Hamburg. Am. J. Enol. Vitic. 50, 334-342.

King, A. \& Dickinson, J.R., 2000. Biotransformation of monoterpene alcohols by Saccharomyces cerevisiae, Torulaspora delbrueckii and Kluyveromyces lactis. Yeast 16, 499-506.
Lalel, H.J.D., Singh, Z. \& Tan, S.C., 2003. Glycosidically-bound aroma volatile compounds in the skin and pulp of 'Kensington Pride' mango fruit at different stages of maturity. Postharvest Biol. Technol. 29, 205-218.

Lambrechts, M.G. \& Pretorius, I.S., 2000. Yeast and its importance to wine aroma - a review. S. Afr. J. Enol. Vitic. 21, 97-129.

Li, X., Yu, B., Curran, P. \& Liu, S.Q., 2011. Chemical and volatile composition of mango wines fermented with different Saccharomyces cerevisiae yeast strains. S. Afr. J. Enol. Vitic. 32, 117-128.

Li, X., Chan, L.J., Yu, B., Curran, P. \& Liu, S.Q., 2012. Fermentation of three varieties of mango juices with a mixture of Saccharomyces cerevisiae and Williopsis saturnus var. mrakii. Int. J. Food Microbiol. 158, 28-35.

Macleod, A.J., Macleod, G. \& Snyder, C.H., 1988. Volatile aroma constituents of mango (cv Kensington). Phytochem. 27, 2189-2193.

Marais, J., 1984. Terpenes in the aroma of grapes and wines: a review. S. Afr. J. Enol. Vitic. 4, 49-56

Mateo, J.J. \& Stefano, R.D., 1997. Description of the $\beta$-glucosidase activity of wine yeasts. Food Microbiol. 14, 583-591.

Mestres, M., Busto, O. \& Guasch, J., 2000. Analysis of organic sulphur compounds in wine aroma. J. Chromatogr. A 881, 569-581.

Misra, G., Pavlosthathis, S.G., Perdue, E.M. \& Araujo, R., 1996. Aerobic biodegradation of selected monoterpenes. Appl. Microbiol. Biotechnol. 45, 831-838

Ollé, D., Baumes, R.L., Bayonove, C.L., Lozano, Y.F., Sznaper, C. \& Brillouet, J.M., 1998. Comparison of free and glycosidically linked volatile components from polyembronic and mono embryonic mango (Mangifera indica L.) cultivars. J. Agric. Food Chem. 46, 1094-1100.

Palmeri, R. \& Spagna, G., 2007. ß-Glucosidase in cellular and acellular form for winemaking application. Enzyme Microb. Tech. 40, 382-389.

Pino, J.A. \& Mesa, J., 2006. Contribution of volatile compounds to mango (Mangifera indica L.) aroma. Flavour Frag. J. 21, 207-213.

Pino, J.A. \& Queris, O., 2011. Analysis of volatile compounds of mango wine. Food Chem. 125, 1141-1146.

Pino, J.A., Mesa, J., Muoz, Y., Mart, M.P. \& Marbot, R., 2005. Volatile components from mango (Mangifera Indica L.) cultivars. J. Agric. Food Chem. 53, 2213-2223.

Rankine, B.C., 1966. Decomposition of L-malic acid by wine yeasts. J. Sci. Food Agric. 17, 312-316.

Reddy, L.V.A. \& Reddy, O.V.S., 2005. Production and characterization of wine from mango fruit (Mangifera indica L.). World J. Microbiol. Biotechnol. 21, 1345-1350.

Reddy, L.V.A., Kumar, Y.S. \& Reddy, O.V.S., 2010. Analysis of volatile aroma constituents of wine produced from Indian mango (Mangifera indica L.) by GC-MS. Indian J. Microbiol. 50, 183-191.

Redzepovic. S., Orlic, S., Majdak, A., Kozina, B., Volschenk, H. \& ViljoenBloom, M., 2003. Differential malic acid degradation by selected strains of Saccharomyces during alcoholic fermentation. Int. J. Food Microbiol. 83, 49-61.

Saerens, S.M.G., Delvaux, F., Verstrepen, K.J., Van Dijck P., Thevelein, J.M. \& Delvaux, F.R., 2008. Parameters affecting ethyl ester production by Saccharomyces cerevisiae during fermentation. Appl Environ. Microbiol. $74,454-461$

Scanes, K.T., Hohmann, S. \& Prior, B.A., 1998. Glycerol production by the yeast Saccharomyces cerevisiae and its relevance to wine: a review. S. Afr. J. Enol. Vitic. 19, 17-22. 
Sivakumar, D., Jiang, Y., \& Yahia, E.M., 2011. Maintaining mango (Mangifera indica L.) fruit quality during the export chain. Food Res. Int. 44, 1254-1263.

Styger, G., Prior, B. \& Bauer, F.F., 2011. Wine flavour and aroma. J. Ind. Microbiol. Biotechnol. 38, 1145-1159.

Suárez-Lepe, J.A. \& Morata, A., 2012. New trends in yeast selection for winemaking. Trends Food Sci. Tech. 23, 39-50.

Swiegers, J.H., Bartowsky, E.J., Henschke, P.A. \& Pretorius, I.S., 2005. Yeast and bacterial modulation of wine aroma and flavour. Aust. J. Grape Wine Res. 11, 139-173.

Takoi, K., Itoga, Y., Koie, K., Kosugi, T., Shimase, M., Katayama, Y., Nakayama, Y. \& Watari, J., 2010. The contribution of geraniol metabolism to the citrus flavour of beer: synergy of geraniol and $\beta$-citronellol under coexistence with excess linalool. J. Inst. Brew. 116, 251-260.

Tharanathan, R.N., Yashoda, H.M. \& Prabha, T.N., 2006. Mango (Mangifera indica L.), "the king of fruits" - an overview. Food Rev. Int. 22, 95-123.
Vaudano, E., Moruno, E.G. \& Stefano, R.D., 2004. Modulation of geraniol metabolism during alcohol fermentation. J Inst. Brew. 110, 213-219.

Wang, Z.X., Zhuge, J., Fang, H. \& Prior, B.A., 2001. Glycerol production by microbial fermentation: a review. Biotechnol. Adv. 19, 201-223.

Wu, Y., Zhu, B., Tu, C., Duan, C. \& Pan, Q. 2011. Generation of volatile compounds in litchi wine during winemaking and short-term bottle storage. J. Agric. Food Chem. 59, 4923-4931.

Yamamoto, T., Shimada, A., Ohmoto, T., Matsuda, H., Ogura, M. \& Kanisawa, T., 2004. Olfactory study on optically active citronellyl derivatives. Flavour Frag. J. 19, 121-133.

Zea, L., Moreno, J., Ortega, J.M. \& Medina, M., 1995. Content of free terpenic compounds in cells and musts during vinification with three Saccharomyces cerevisiae races. J. Agric. Food Chem. 43, 1110-1114.

Zemni, H., Souid, I., Fathalli, N., Salem, A.B., Hammami, M., Ghorbel, A \& Hellali, R., 2007. Aromatic composition of two Muscat grape cultivars cultivated in two different regions of Tunisia. Int. J. Fruit Sci. 7, 97-112. 